\title{
Comparative Evaluation of Erosive Potential of Common Acidic Beverage on Esthetic Restorative Materials -A SEM Study
}

\author{
Monika $^{1}$, Rajan Dhawan ${ }^{2}$ and Shivani Dhawan ${ }^{3}$ \\ ${ }^{1}$ National Dental College and Hospital, Derabassi (Mohali), Punjab, India \\ ${ }^{2}$ Department of Conservative Dentistry, M.M College of Dental Sciences \& Research, Mullana (Ambala), \\ Haryana, India \\ ${ }^{3}$ Department of Periodontology, M.M College of Dental Sciences \& Research, Mullana (Ambala), \\ Haryana, India
}

Correspondence should be addressed to: Rajan Dhawan; endorajan@gmail.com

Received Date: 24 September 2013; Accepted Date: 6 December 2013; Published Date: 31 May 2014

Academic Editor: Werner J. Finger

Copyright (C) 2014 Monika, Rajan Dhawan and Shivani Dhawan. Distributed under Creative Commons CC-BY 3.0

\begin{abstract}
Thus the aim of present study was to assess the erosive potential of commonly used beverage over esthetic restorative material, which are traditional GIC and composite. In this study two tooth colored restorative materials were chosen and erosive materials selected were Orange juice and Yakult. Extracted maxillary anterior teeth were taken. All crowns were stored in 5.25\% sodium hypochlorite solution until usages. Standardized U shaped cavities were prepared on labial aspect of these specimens and divided into 2 groups with 18 samples each.

Group A restored with GIC and Group B restored with composite. Each group that was previously restored further divided into 3 subgroups with 6 samples each depending upon type of erosive solution used to treat them. All samples were evaluated under SEM at magnification of 400x.

The erosive damage of material surface was compared using SEM images. The degree of damage to esthetic material by erosive acids was assessed within five ranks criteria.

Results show the value of resin containing materials in providing surface protection to tooth material in patients experiencing continuous severe endogenous or exogenous erosion.
\end{abstract}

Keywords: Erosion, Acidic beverages, Esthetic.

Cite this Article as: Monika, Rajan Dhawan and Shivani Dhawan (2014), "Comparative Evaluation of Erosive Potential of Common Acidic Beverage on Esthetic Restorative Materials -A SEM Study," Journal of Research and Practice in Dentistry Vol. 2014 (2014), Article ID 739216, DOI: 10.5171/2014.739216 


\section{Introduction}

Dental erosion is relatively a new risk factor for dental health, introduced by today's life style that affects people of all ages. Erosion is defined as loss of tooth substance by chemical processes not involving bacteria caused by a variety of extrinsic and intrinsic factors ${ }^{1}$.The prevalence of erosion on the palatal surfaces of primary molars is about $50 \%$, and in the permanent is $31 \%$. Clinically, these erosive lesions appear as broad concavities within smooth surface enamel, cupping of occlusal surfaces or incisal grooving with dentin exposure, and increased incisal translucency.

Dental erosion is a multi-factorial condition with both extrinsic and intrinsic causes. The most common extrinsic factors that can lead to erosion are dietary acids, such as fruit juices, carbonated drinks, and sports drinks, oral hygiene products and medications with a low $\mathrm{pH}$, such as toothpastes, fluoride rinses, and vitamin $\mathrm{C}$ tablets. ${ }^{2}$ Intrinsic factors involved in dental erosion are gastric acids that are regurgitated into the mouth like in case of gastro esophageal reflux disease (GERD) or with chronic excessive vomiting such as patients with anorexia, bulimia, alcoholism or gastrointestinal disorders.

But nowadays out of all these extrinsic and intrinsic factors, the increasing consumption of acidic beverages and fermented milk beverages is the most common etiological factor for dental erosion. Common beverages like Cola soft drinks affect the marginal integrity and surface micromorphology of the Dyract AP and Fuji II LC restorative materials. ${ }^{3}$ Fermented milk beverages have acidic $\mathrm{pH}$, sugar and Lactobacillus or Bifidobacterium lactobacillus which produces acids and leads to dental erosion whereas acidic beverages like cola drinks, fruit juices contain citric acid which has high erosive potential and leads to dental erosion. ${ }^{2}$ Bieri et al. showed that rats fed orange juice for one week had tooth surface loss comparable with that seen with citric and acetic acids. ${ }^{4}$
Although there are number of factors of particular beverage which determine the degree of erosion like its fluoride and phosphate content, type of acid involved, form in which delivered, frequency of intake, duration and amount of acid, but still the ph. of particular beverage is considered to be the most important risk factor of erosion. Hughes et al. (2002) concluded that the decreasing $\mathrm{pH}$ and increasing acid concentration of various soft drinks were correlated with the increased dental erosion incidence.

Yakult is a leading brand of probiotic drink all over the world. Yakult is a fermented milk drink containing Lactobacillus casei Shirota (LcS), a unique probiotic strain discovered in 19305. Lactobacillus sp. is bacterium that belongs to a group generally referred to as lactic acid bacteria. Hence, this agent may have an erosive effect on the restorations.

The management of dental erosion consists of two essential components: prevention andtherapy. The key elements in the prevention of dental erosion irrespective of the etiology of erosion include, patient education and compliance with diet modification, occlusal splints etc. The loss of tooth tissue sometimes needs active treatment along with preventive measures. Initially, when these lesions are limited to enamel only, composite restorations are the treatment of choice for esthetic needs, and prevent further progression of disease. Later, when these defects involve dentine and lead to hypersensitivity, Glass ionomer restorations become the preferred treatment of choice to reestablish tooth structure, function, and esthetic as well as to control hypersensitivity.

The longevity of these restorations depends on their material properties like wear resistance, which is usually affected by the presence of acidic condition in mouth after the consumption of these acidic beverages ${ }^{6}$. Once in the oral cavity, restorative materials are exposed to a variety of adverse conditions including the presence of acidic foods and drinks (Chanothai et al., 2011). So, 
over a period of time all these restorations undergo degradation ${ }^{7}$

The null hypothesis tested was that there was no difference in the surface micromorphology of the two restorative materials (GIC and composite) after immersion in the acidic agents being tested.

Thus, the aim of the present study was to assess the erosive potential of commonly used beverage orange juice (REAL)having ph.
2.8-4 and Yakult over esthetic restorative material which are traditional GIC and composite, commonly used to restore these erosive defects.

\section{Material \&Method}

For this study, two commercial available tooth colored restorative materials were chosen. These included Traditional Glass Ionomer Cement(3M Z350) and Composite (GC Fuji IX GP).

\begin{tabular}{|l|l|l|}
\hline MATERIAL & COMMERCIAL BRAND & COMPOSITION \\
\hline RESIN COMPOSITE & 3M Z350 & bis-GMA, \\
& & UDMA, \\
& & TEGDMA \\
& & bis-EMA \\
& & silica filler \\
& & ggregated zirconia/silica cluster filler \\
\hline GLASS INOMER & GC Fuji IX GP & Alumino silicate glass (CAS not listed) \\
CEMENT & & $95 \%$ powder (5\%) \\
& & Polyacrylic acid powder \\
\hline
\end{tabular}

The erosive material selected was Orange juice (REAL) containing citric acid and Yakult (Probiotic solution). This Probiotic solution has acidic $\mathrm{pH}$, sugar and Lactobacillus or Bifidobacterium that produce organic acids and cause erosion.

\section{Preparation of Tooth Specimen for Restoration and Method of Immersion}

Thirty-six extracted maxillary anterior teeth were taken from the oral surgery department of the National dental college and hospital Dera Bassi. The crown of these teeth was separated from their roots using slow speed sectioning machine. All crowns were inspected to ensure no visible cracks or deep pits present and stored in $5.25 \%$ sodium hypochlorite solution until usages. Standardized U shaped cavities having $4 \mathrm{~mm}$ width and $2 \mathrm{~mm}$ depth were prepared on labial aspect of these specimens and divided into 2 groups.

Group A $(n=18)$ restored with traditional GIC (GC Fuji IX GP)
Group B (n=18) restored with composite (3 M Z350)

All restorations had cellulose matrix bands applied during placement, were stored in humid environment, and after seven days all the specimens were polished by using medium, fine, and superfine discs (Sof-Lex, 3MESPE, MN, USA) rotating in one direction at slow speed.

Each group that was previously restored, further divided into 3 subgroups depending upon type of erosive solution, used to treat them.

Sub group $1(n=6)$-treated with orange juice

Sub group $2(n=6)$-treated with Yakult

Sub group $3 \quad(n=6)$-treated with saline (control group)

Then equal numbers of samples $(n=3)$ from each subgroup were treated with their 
respective solution for a period of 30 minutes (i.e. for 5 minutes, 3 times /day over period of 2 days), and 75 minutes (5 minutes 3 times/day over a period of 5 days)at temperature of $37^{\circ} \mathrm{c}$.

\section{Preparation of Sample for Scanning Electron Microscope}

For preparation of sample for SEM each crown, which was previously immersed in erosive solution, was sectioned horizontally through the middle of restoration. All samples were fixed in a solution containing $1.25 \%$ gluteraldehyde, 4\%sucrose,4\%paraformeldehyde and phosphate buffered saline. This was followed by washing in a sucrose/PBS solution, and dehydrated at increasing concentration of ethanol to 100 percent. All samples were then mounted on a metal stub and coated with gold and carbon in preparation for SEM analysis using scanning electron microscope at a magnification of $400 \mathrm{x}$.

\section{Method of Assessment of Degree of Erosion}

The erosive damage of the material surface was compared using SEM images. The degree of damage to esthetic material by erosive acids was assessed within five ranks by using the following criteria: -

Score 0 -surface intact

Score 1-minimal changes

Score 2-initial etching with cracking

Score 3-crystal and matrix seen with or without cracking

Score 4-severe erosion with crystal separated from matrix

\section{Results}

Table -1 Mean Ranking Score of Erosive Damage to the Restoration Surface by Two Erosive Solutions and Saline (Negative Control)with Time

\begin{tabular}{|ll|lc|lc|lc|}
\hline Solution & & \multicolumn{2}{|l|}{ Yakult } & \multicolumn{2}{|l|}{ Orange Juice } & \multicolumn{2}{l|}{ Saline } \\
\hline $\begin{array}{l}\text { Contact } \\
\text { (minutes) }\end{array}$ & Time & 30 & 75 & 30 & 75 & 30 & 75 \\
\hline GC Fuji IX GP & & 2 & 3 & 3 & 4 & 0 & 1 \\
\hline $\begin{array}{l}\text { Composite } \\
\text { 3M Z350 }\end{array}$ & 1 & 1 & 1 & 2 & 0 & 0 \\
\hline
\end{tabular}

Table 1 records the ranked degree of surface damage sustained by each material following different period of exposure to real orange juice, Yakult and saline as a control. These are ranked 0-4 according to criteria listed previously. Real orange juice showed to cause severe damage to GC Fuji IX GP and 3M Z350, on the other hand, Probiotic solution
Yakult showed less erosive damage to both GC Fuji IX GP and 3M Z350. Very minimal changes were seen in traditional Glass Ionomer GC Fuji IX GP and 3M Z350 restorative materials in saline. It was also recorded that GC Fuji IX GP undergo more severe erosive damage as compared to $3 \mathrm{M}$ Z350 in both solutions used. 

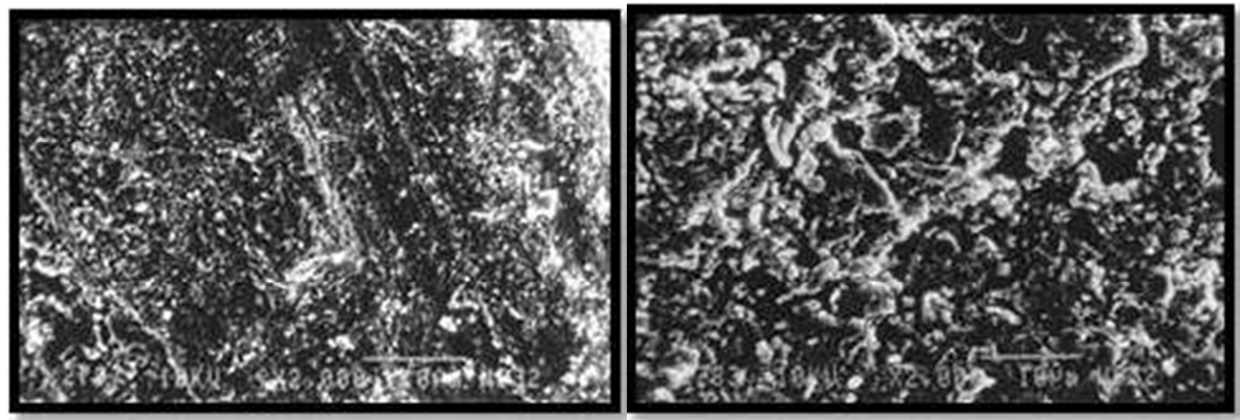

Figure 1 and 2 show the SEM pictures of surface changes on GC fuji IX GP and 3M ESPe when immersed in erosive solution at different exposure time periods.

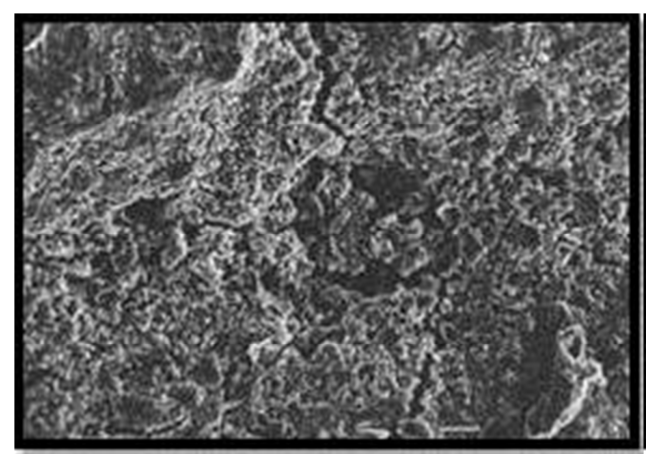

Figure - (1.1a)

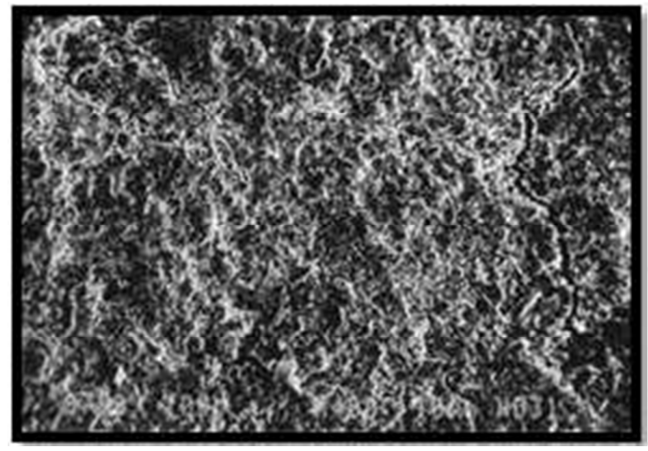

Figure - (1.2a)

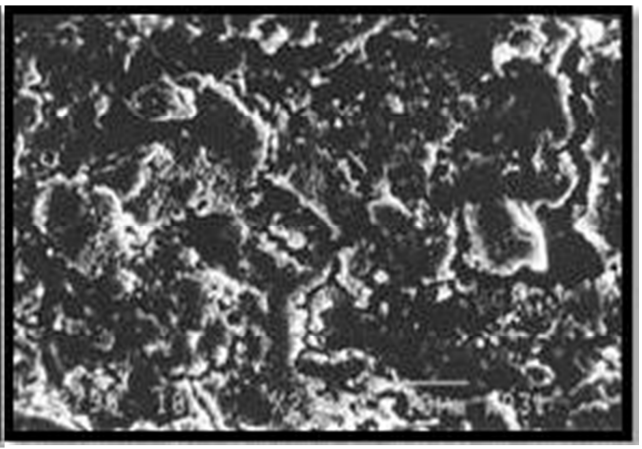

Figure - (1.1b)

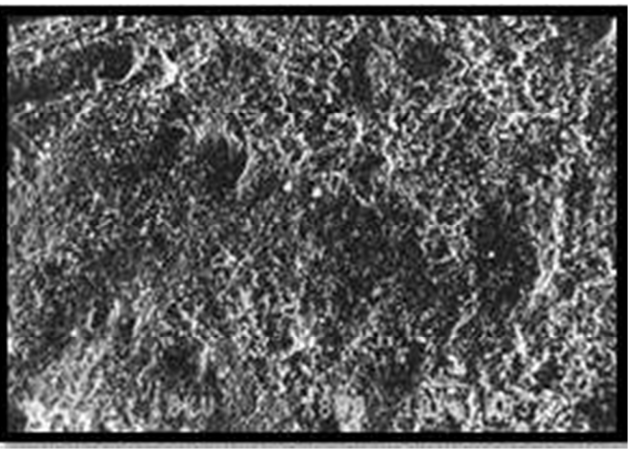

Figure - (1.2b)

Monika, Rajan Dhawan and Shivani Dhawan (2014), Journal of Research and Practice in Dentistry, DOI: $10.5171 / 2014.739216$ 


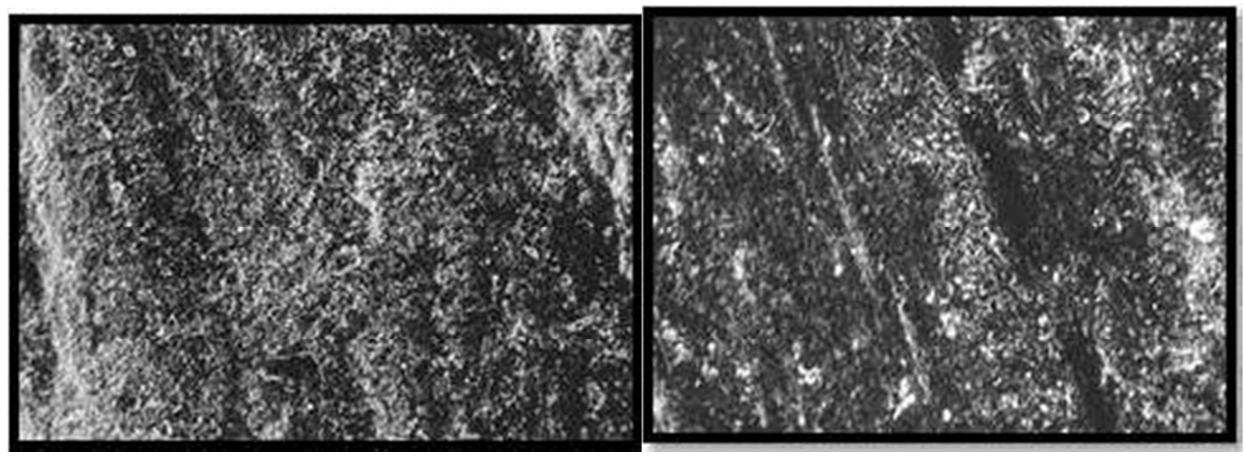

Figure - (1.3a)

Figure - (1.3b)

Figure1.SEM Pictures of Surface Changes on GC Fuji IX GP (1.1a) in Yakult Solution at 30 Minutes and(1.1b) in Yakult at 75 Minutes- (1.2a) in Orange Juice at 30 Minutes and (1.2b) in Orange Juice at 75 Minutes - (1.3a) in Saline Solution at 30 Minute and (1.3b) in Saline Solution at 75 Minutes

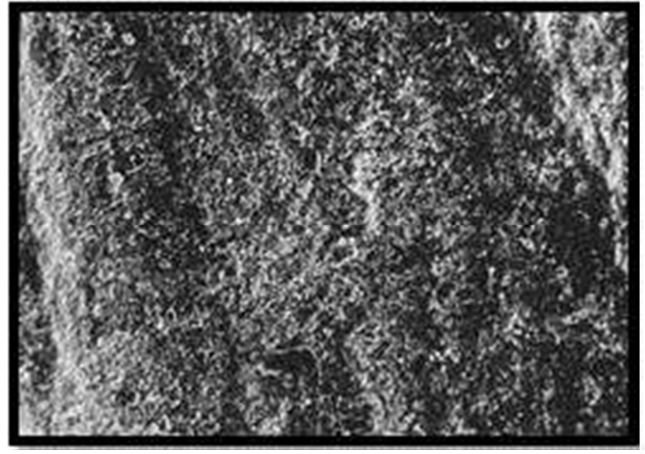

Figure - (2.1a)

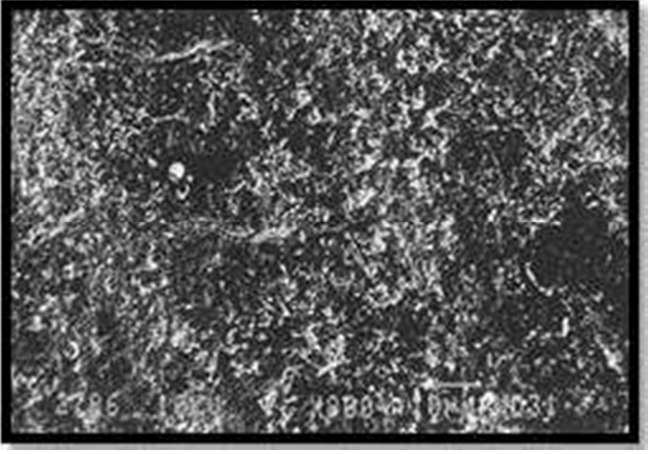

Figure - (2.1b)

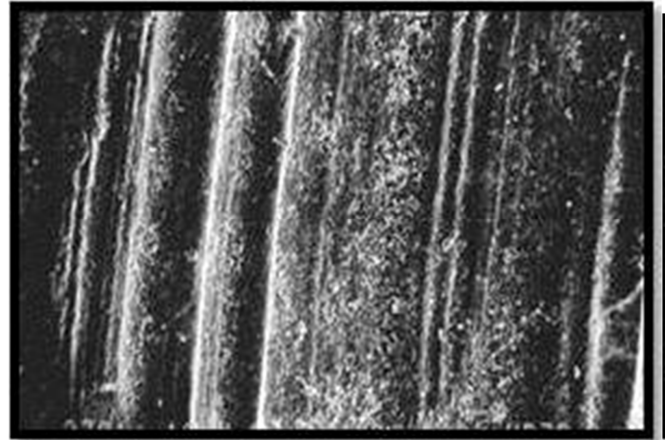

Figure-(2.2a)

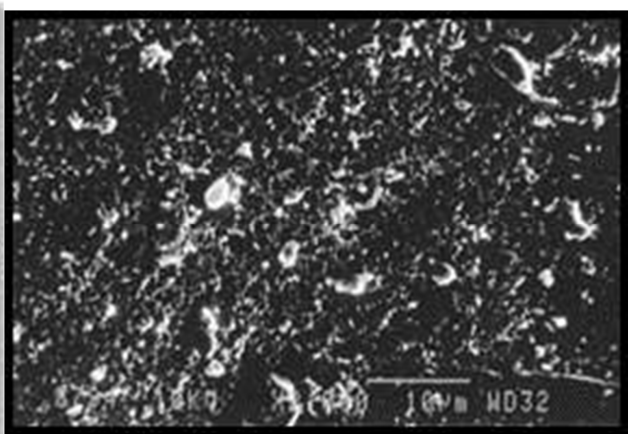

Figure - (2.2b)

Monika, Rajan Dhawan and Shivani Dhawan (2014), Journal of Research and Practice in Dentistry, DOI: $10.5171 / 2014.739216$ 


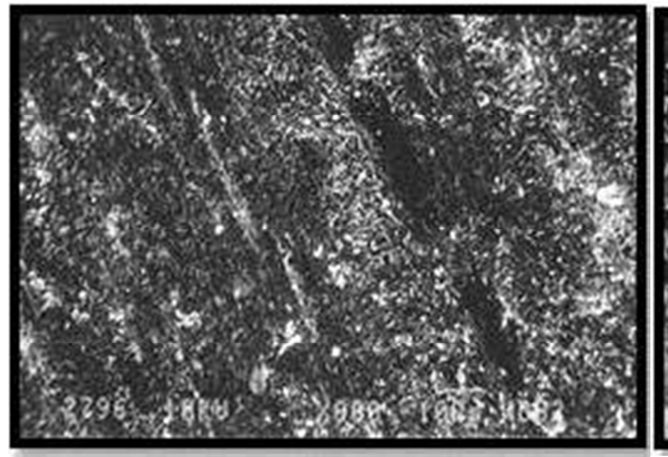

Figure - (2.3a)

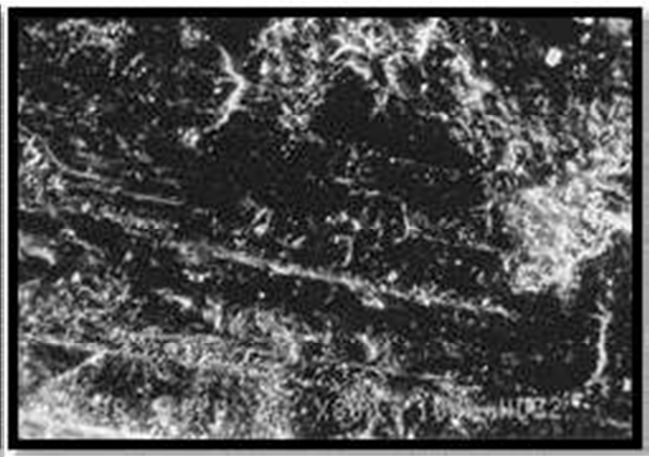

Figure - (2.3b)

Figure2.SEM Pictures of Surface Changes on Composite (3M Z350) (2.1a) in Yakult Solution at 30 Minutes and (2.1b) in Yakult Solution at 75 Minutes- (2.2a) in Orange Juice at 30 Minute and (2.2b)in Orange Juice at 75 Minutes - (2.3a) in Saline Solution at 30 Minute and(2.3b) in Saline Solution at 75 Minutes

\section{Discussion}

Oral cavity is vulnerable to varying environments such as temperature changes and acidic -base conditions. The restorative material used for restoration should either resist or show minimal changes during these conditions ${ }^{8}$.In the present study, this method was performed solely to examine erosion by the static immersion of the restorative materials in the solutions over a period of 5 days, and to detect subsequent changes in surface roughness.

Composite restorations are more resistant to the acidic gastric juice than glass ionomer cement $^{9}$. In the present study, two restorative materials, traditional glass Ionomer GC Fuji IX GP and composite (3M Z350) were used for restoring teeth that have erosive conditions. Results of the present study showed that Traditional GIC (GC Fuji IX GP) had more erosive damage in both real juice as well as Yakult solution as compared to composite (3M Z350). The possible reasons for those results might be the difference in the composition of the materials and the set structure of each material, including the titratable acidity of the acidic agents. Erosive damage in case of traditional glass ionomer cement occurs due to matrix dissolution peripheral to glass particles of the glass ionomer, which could result from the dissolution of the siliceous hydrogel layer ${ }^{8}$. On the other hand, surface roughness in case of $3 \mathrm{M} \mathrm{Z350} \mathrm{occurred} \mathrm{due}$ to the softening of Bisphenol-A-glycidyl methacrylate (Bis-GMA)-based polymers, which could result from the leaching of diluent agents, such as Triethylene glycol dimethacrylate (TEGDMA) by the acid attack present in Real juice ${ }^{8}$.The results of the present study revealed that the immersion of restorative materials in acidic beverages like orange juice can cause surface roughness, which increases with time.

It is also seen that real juice had more erosive potential as compared to Yakult and saline used as negative control. Orange and apple juice contain carboxylic acids, which are capable of chelating ions, such as calcium, and forming complexes of reasonable solubility in water hence show more erosive potential as compared to yakult ${ }^{5}$. McKenzie and others showed a greater reduction in surface hardness for apple and orange juice when compared to colas, the beverage used in this study.

The low $\mathrm{pH}$ of fermented milk beverages like Yakult along with other factors, including the 
physical and chemical properties that affect the adhesion of microorganisms to the dental surface, the stimulation of salivary flow, the buffering capacity of beverages and the presence of fluoride, calcium and phosphate was associated with the onset of caries lesions and erosions in the oral cavity, as demonstrated by Shibata et al. (1977). The Yakult used in the current study had ph. 3.51 along with Buffering Capacity $779.2 \mu \mathrm{L}$, Fluoride concentration $0.148 \mu \mathrm{gF} / \mathrm{g}$, Phosphorus concentration $0.5029 \mathrm{mg} \mathrm{P} / \mathrm{g}$ that makes it less erosive as compared to real juice. ${ }^{2}$

It is known that, during consumption, food or drink only comes in brief contact with tooth surfaces before it is washed away by saliva. To simulate a similar condition in the current study, the total time exposure of specimens to acid was kept 5 minutes, 3 times a day and for 5 days at room temperature to promote significant micro hardness alterations and differences among the study materials.

Even though these data point to severe vulnerability in the glass ionomer cement material, but this material retains some preventive protection of enamel while degrading by releasing fluoride ion on degradation, but the concentration of fluoride ion released from degrading glass ionomer cements are insufficient to more significantly inhibit the erosive demineralization process in enamel as studied by Featherson and Zero (1992). ${ }^{4}$ So it is evident that, while GIC provide some protection in severe acidic environment, it is preferable to use them in a close sandwich restoration rather than leave them exposed directly to this environment.

So overall, results show the value of resin containing materials in providing surface protection to tooth material in patients experiencing continuous severe endogenous or exogenous erosion.

\section{References}

1- Sales-Peres, S. H. C., Magalhãe, A. C. et al. (2007). "Evaluation of the Erosive
Potential of Soft Drinks," European Journal of Dentistry. January 2007 vol.1.

2- Lodi, C. S., Sassaki, K. T., Fraiz, F. C., Delbem, A. C. B. \& Martinhon, C. C. R. (2010). "Evaluation of Some Properties of Fermented Milk Beverages that Affect the Demineralization of Dental Enamel," Brazilian Oral Research. 2010. Jan-Mar; 24(1): 95-101.

3- Narsimha, V. V. (2011). 'Effect of Cola on Surface Micromorphology and Marginal Integrity of Resin Modified Glass Ionomer and Compomer Restoration An in Vitro Study,' People's Journal of Scientific Research. 2011, july; Vol. 4(2), 34-40.

4- Gray, A., Ferguson, M. M. \& Wall, J. G. (1998). "Wine Tasting and Dental Erosion. Case Report," Australian Dental Journal 1998; 43:(1):32.

5- Kopp-Hoolihan, L. (2001). "Prophylactic and Therapeutic Use of Probiotics: A Review," Journal of the American Dietetic Association 2001. 101(2): 229241.

6- Francisconi, L. F., Honório, H. M., Rios, D., Magalhães, A. C., Machado, M. A. A. M. \& Buzalaf, M. A. R. (2008). "Effect of Erosive $\mathrm{pH}$ Cycling on Different Restorative Materials and on Enamel Restored with These Materials," Operative Dentistry, 2008, 33-2, 203208.

7- Hengtrakoola, C., Kukiattrakoonb, B. \& Kedjarune-Leggatc, U. (2011). "Effect of Naturally Acidic Agents on Microhardness and Surface Micromorphology of Restorative Materials," European Journal of Dentistry January 2011 - Vol.5.

8- Zaki, D. Y. I., Hamzawy, E. M. A., Abd El Halim, S. \& Amer, M. A. (2012). "Effect of Simulated Gastric Juice on Surface 
Characteristics of Direct Esthetic Restorations," Australian Journal of Basic and Applied Sciences, 2012, 6(3): 686-694.

9- Wan Bakar, W. Z. \& Mclntyre, J. (2008). "Susceptibility of Selected Tooth Coloured Dental Materials to Damage by Common Erosive Acids," Australian Dental Journal 2008: 53:226-234.

10- Gambon, D. L., Brand, H. S. \& Nieuw Amerongen, A. V. (2010). "Soft Drink, Software and Softening of Teeth - A Case Report of Tooth Wear in the Mixed Dentition Due to a Combination of Dental Erosion and Attrition," The Open Dentistry Journal, 2010, 4, 198-200.
11- Lussi, A., Hellwig, E., Zero, D. \& Jaeggi, T. (2006). "Erosive Tooth Wear: Diagnosis, Risk Factors and Prevention," American Journal of Dentistry, Vol. 19, No. 6, December, 2006. 